\title{
Experimental study on local bond stress-slip relationship in self- compacting concrete
}

Marian Sabau, loan Pop, Traian Onet

\begin{abstract}
This paper summarizes the results of an experimental study on local bond stressslip relationship of deformed reinforcing bars embedded in self-compacting concrete, considering the effect of concrete confinement by transverse reinforcement. In this study were cast 104 specimens by using self-compacting concrete and vibrated concrete. Pull-out tests were performed on deformed bars with short anchorage length $(\mathrm{ld} \leq 5 \emptyset)$. The parameters analyzed were the concrete type, the confining reinforcement, the bar diameter and the anchorage length of bar. The results of this study showed that the ultimate bond strength was higher for self-compacting concrete compared to vibrated concrete, and the slip corresponding to the ultimate bond strength was higher for vibrated concrete. Also, it has been observed higher ultimate bond strength for smaller bar diameter. In general a decreasing tendency of the ultimate bond strength with increased anchorage length of bar was found, yet with some exceptions. All the specimens confined with transverse reinforcement had a pull-out failure, while the unconfined specimens had a splitting failure, hence the presence of transverse reinforcement changed the type of bond failure from unfavorable (splitting), to a favorable one (pull-out). A new bond model for pull-out failure based on regression analysis of the experimental data from this study was proposed, considering the favorable effects that the confining reinforcement and relative rib area have on bond strength.
\end{abstract}

\section{Keywords}

Self-compacting concrete, Bond strength, Confining reinforcement, Pull-out test, Anchorage length, Relative rib area 